\title{
Ecological and Sustainability Issues In Earth Construction
}

\author{
Olusola Oladapo Makinde \\ Department of Architecture, Ladoke Akintola University of Technology, Ogbomosho, Oyo State, Nigeria
}

\begin{abstract}
This paper study ecological and sustainability issues in earth construction for housing purpose with a view to enlighten the people on what we need to be concern about in using earth materials. The study looked at environmental factors; strategies for sustainable ecological development and benefits of rammed earth as ecological stable material. This paper examined the effect of the usage of earth materials for constructions process in building and it sustainability, the impacts on the environment and way of preventing the possible implications that may result when used. The paper makes strategies and recommendations that could be adopted to sustain the environment.
\end{abstract}

Keywords - Earth Construction; Ecological Issues; Environmental factors; Housing Sustainability.

\section{Introduction}

This paper focuses on ecological issues in building constructed with mud brick (adobe), rammed earth cob, compressed earth block or other methods of earthen construction and serves as a database for the discussion and dissemination of events, resources, and images of earth architecture in the context of contemporary architecture culture. Many Architects, construction and building Engineers are ill-equipped by their training to deal with the emergent issues of global warming, acid rain and other ecological and environmental influences. Architects have the power to influence the consumption of energy in construction in the face of raised awareness of the potential damage to our ecological future. Concern with the ozone layer, global warming, acid rain, diminishing rain forests and the depletion of vital reserves, and the ever increasing demand for energy, has meant that ecology and the environment is rapidly becoming one of the most powerful influences on the design process. This is leading to an emerging trend based on a response to these criteria. Whilst everybody talks about ecological building, few Architects, construction engineers and building services engineers are truly able to deal with these issues. Their training has not prepared them. The Habitat conferences and the Rio Earth Summit have already helped to raise international awareness of the potentially bleak ecological future of our planet if current trends continue unaltered (UN, 1997). There is no question that Architects influence energy consumption in construction (Civilengineergroup, 2011). There is no single prescriptive method of achieving sustainability. Irrespective of the contrasting climatic conditions the material infrastructure is completely different. In Nigeria earth and timber are in plentiful supply and it's not surprising therefore that it is a common feature in Ecological Architecture. Taking account of regional, national and international variations in materials, and supply chain infrastructure the study illustrate the potential implications on the use of earth construction in environmentally responsible Architecture.

The work of Architects who aim to build with ecology and the environment in mind, are those who use earth or organic forms. They see traditional and vernacular methods and materials as the panacea for all environmental ills. They contribute to the protection of the environment. They use modern technology and materials available to them in such a way as to minimise the strain on the earth (Civilengineergroup, 2011). One of the most commonly adopted measures for saving environmentally precious resources is to fully utilise whatever is in free supply such as air, wind, passive air-flows, water, sea, rivers, dams, ground water; sun; passive and active systems; earth; thermal and acoustic insulation, cheap material; fauna and flora; and combinations of them. The material such as clay, gravel, sand, silt, soil, loam, mud is everywhere. The ground we walk on and grow crops in also just happens to be the most widely used building material on the planet. Civilizations throughout time have used it to create stable, warm, low-impact structures.

\subsection{Related Ecological Issues}

Ecology is defined as the environment and its association with the living organisms. Ecology is the study of life and the interactions between organisms and the natural environment. Ecology issues have always been a major concern of mankind. According to Buzzle (2011), our environment forms an integral part of our life and a clean and healthy environment becomes a requisite for a healthy living. It is we, human beings, who should take efforts to deal with the environmental issues and show a deep concern towards ecology. Here is a list of the different ecology issues that we need to care when using materials for construction. There is pollution of soil, water, and air; habitat destruction and species loss; disease and other issues that could result from the use of materials for construction purposes. These include among others: Health Related Issues; Erosion; Acid Rain; 
Air Pollution; Noise Pollution; Water Pollution; Climate Change Earthquakes; Environmental Pollution; Endangered Species; Global Warming; Greenhouse Effect; Hurricanes; Landslides: Others Are: Melting Glaciers; Ozone Depletion; Recycling; Soil Conservation and Wildlife Conservation.

\section{Earth Construction}

According to Jennifer (2010), earth construction is the practice of building with unfired, untreated, raw earth. It has been successfully used around the world for over 11,000 years, and it is estimated that around half the world's population today live and work in earth buildings.

\subsection{Earth Materials}

The type of materials available locally will of course vary depending upon the conditions in the area of the building site. In many areas, indigenous stone is available from the local region, such as limestone, marble, granite, and sandstone. Ideally, stone from the building site can be utilized, depending on the stone type, it can be used for structural block, facing block, pavers, and crushed stone. Most brick plants are located near the clay source where they use to make brick. Bricks are moulded and baked blocks of clay. Brick products come in many forms, including structural brick, face brick, roof tile, structural tile, paving brick, and floor tile. Caliche is a soft limestone material which is mined from areas with calcium-carbonate soils and limestone bedrock. It is best known as a road bed material, but it can be processed into an unfired building block, stabilized with an additive such as cement. Other earth materials include soil blocks typically stabilized with a cement additive and produced with forms or compression. Rammed Earth consists of walls made from moist, sandy soil, or stabilized soil, which is tamped into form work. Walls are a minimum of 12" thick. Soils should contain about $30 \%$ clay and $70 \%$ sand.

\subsection{Types of Earth Building}

The techniques and methods for earth construction vary with culture, climate and resources, but within the sustainable building movement they can be categorised as: cob, rammed earth, and wattle-and-daub, light straw, earth bags, earth bricks, earth floors, and earth plasters and finishes.

Cob Building: The word cob means "lump or rounded mass". Cobs are made from moist subsoil mixed with sand and straw, and kneaded into stiff mud loaves that are then rammed together by hand to form a selfdesigned structure. Cob dries almost as hard as concrete and can be used for self-supporting, load-bearing walls. Thick walls are built (up to 6 feet wide) by working in layers, letting each one harden before adding the next layer. The wall is then plastered with clay or lime plasters, or left unfinished, but in wet climates an overhang or shelter might be necessary to protect an unfinished wall. Building with cob is simple, cheap and requires few tools other than hands and imagination. It can be time-consuming, but there are many advantages to cob including its extreme durability, strength, fire-resistance, insulation properties and the ease with which it can be aesthetically shaped and sculpted.

Rammed Earth: Compaction Moist subsoil is layered into a temporary formwork (shuttering) and then rammed (tamped) for by manual or mechanical means. The layers can be rammed continually until the wall is complete, with no need to wait for each layer to dry out. The walls are then allowed to dry naturally once the frame is removed. Rammed earth is stronger than cob, but more expensive because of the shuttering required.

Wattle-and-Daub: One of the oldest earth techniques, this involves weaving thin branches together (wattle) as a support for mud plaster (daub). It does not have the super-insulation properties of straw-bale or clay-straw, but provides good thermal mass.

Light Earth or Straw Clay: A combination of cob and rammed earth, this involves coating loose straw or other fibrous material with a clay slip that is rammed tightly in layers into a timber frame. It is lighter than cob and has a higher insulation value, but is not as strong and must only be used as an infill with the timber frame. The walls are allowed to dry before final plastering takes place. Light earth has also been used between rafters as roof insulation, and as insulation underneath earthen floors.

Earth bags: These are soil-filled sacks that can be used to create walls and dome structures. This technique is still being explored, but seems to offer a quick and easy method for natural building, and may be especially suitable for temporary or disaster relief housing. Moist soil is put into a burlap sack or plastic bag, stacked into place on a wall, and then compressed using a simple hand tool. Earth bags are increasingly being used as foundations for cob and straw bale houses.

Earth Bricks: These are made from an earth and straw mix, similar to cob, placed into moulds to form bricks or blocks, and then dried out in the sun. The most popular type is adobe brick. Normal bricklaying techniques 
are used, using an earth or lime mortar. Earth bricks have load-bearing structural properties but provide poor insulation (Civilengineergroup, 2011).

Earthen Floors: This involves pouring one or more layers of an earth mixture over a substrate of gravel, pumice or sand. The site needs to be carefully prepared first to ensure drainage and low moisture. Hardening agents are sometimes added such as blood, manure or lime. When the floor is completely dry, it is sealed with successive applications of linseed oil and turpentine, and waxed for protection (Jennifer, 2010).

Earth Plasters and Finishes: These are made from clay slips or lime and are becoming increasingly popular. They are non-toxic, and allow walls to breathe, so that any moisture trapped inside the walls can evaporate out.

\section{Rammed Earth as Case Study and the Ecological Issues Involved}

Modern day Rammed Earth is a building technique in which walls are formed by compacting small layers of sand, clay, cement and water into reusable wall forms. The mixture is allowed to set, usually overnight, and the form is removed. The finished result is a high density, aesthetically pleasing, and structurally superior built wall. Rammed earth walls are 2 feet thick; and although the most economical wall height is 8 feet, it is build up to 14 feet in height. They stand up to the elements far better than adobe or wood-frame houses. They are extremely solid and sound resistant. They are considerably more energy efficient, staying cool in the summer and warm in the winter. They are fireproof, waterproof, and termite-proof. They are environmentally friendly, using up to 50\% less lumber than a conventional frame house. They tend to work hand in hand with solar-oriented designs. Most rammed earth homeowners will agree that the greatest advantage of all is the peaceful, serene atmosphere felt throughout the home, regardless of the outdoors. The consistency, texture and natural colour of our rammed earth walls allow the homeowner the flexibility of finishing the interior and exterior using an array of different methods. Some prefer the natural look of rammed earth, while others prefer to have the exterior walls stuccoed and the interior walls plastered (Earth and Sun Construction, 2008).

According to USC (2007), Rammed Earth is a technique used in the building of walls using the raw materials of earth, chalk, lime and gravel. It is an ancient building method that has seen a revival in recent years as people seek more sustainable building materials and natural building methods. Rammed earth walls are simple to construct, incombustible, thermally massive, very strong and durable. However, they can be labourintensive to construct without machinery (powered rammers), and, if improperly protected or maintained, they are susceptible to water damage. The availability of useful soil and a building design appropriate for local climatic conditions are the factors which favour its use. Building a rammed earth wall involves compressing a damp mixture of earth that has suitable proportions of sand, gravel and clay (sometimes with an added stabilizer) into either an externally supported frame, creating a solid wall of earth, or into blocks. Historically, stabilizers such as lime or animal blood were used to stabilize the material, whilst modern construction uses lime, cement or asphalt emulsions. Some modern builders also add coloured oxides or other items such as bottles or pieces of timber to add variety to the structure.

\subsection{Rammed Earth Specifications}

According to USC (2007), properly constructed rammed earth walls are unaffected by rain, wind, fire or termites. Load Bearing Rammed earth walls are generally 18 to 24 inches thick and Non-Load Bearing Rammed earth walls are generally 10-14 inches thick. Rammed earth compressive strength is approximately 300psi. Rammed earth walls can be stuccoed, plastered, or left bare to expose the soft, rhythmic layers of earth, like sediment lines in sandstone. Rammed earth can be used in any style building with any kind of roof. Properly designed, a rammed earth structure will store the sun's heat each winter and block it each summer, yielding energy savings year after year. Rammed earth will begin to cure immediately, and can take from several months to several years, depending on weather and humidity to complete the process.

\subsection{Environmental Factors for Consideration in Earth Construction}

Soils Consideration: Rammed earth may have originally been developed in climates where humidity and rainfall did not permit the production of soil block. For soil block to cure uncovered, there must be at least 10 rain-free days. Soils with high clay content may be more suitable for ramming, as they tend to crack in blocks when curing. Rammed earth soil mixes must be carefully prepared by screening, pulverizing, and mixing to ensure a uniform mix and to break up any clumps. The soil mix needs to be carefully balanced between clay, sand, and aggregate, a wider range of soils are suitable when a small amount of cement ( $6 \%$ of mixture) is added. Stabilized Rammed Earth is a strong masonry product which provides excellent thermal mass. Earth is a widely available building material with virtually no side effects associated with harvesting for use in construction. The earth used is typically subsoil, leaving top soil readily available for agricultural uses and often the soil can be used on the site where the construction takes place there by reducing cost and energy used for transportation. 
Transporting the soil mix to the forms is a demanding task. Large quantities of soil must be moved and transported vertically for placement in the forms. This process is not the same as pouring concrete, because the material is not liquid. Chemical stabilization using lime, Portland cement, and industrial waste products, rich in cementing agents, have been used in an attempt to improve the strength of the rammed earth.

Co2 Emissions: Using rammed earth as a construction material greatly reduces the amount of $\mathrm{CO} 2$ released during the construction of the building. The manufacture of cement requires the burning of limestone and produces $\mathrm{CO} 2$ as a waste product, around $10 \%$ of global $\mathrm{CO} 2$ emissions are from the cement industry. In using soil taken directly from the site, there is no transport requirement, directly reducing $\mathrm{CO} 2$ emissions and taking vehicles off the road.

Thermal Performance: The high thermal mass of rammed earth walls mean they act to naturally regulate the internal temperature of a building, and if a rammed earth wall is designed into the heating system of a structure, the energy required to both heat and cool the building can be greatly reduced, which further reduces the $\mathrm{CO} 2$ emissions of the building. Rammed earth naturally regulates the internal relative humidity of the building, producing an improved air quality, and this contrasts greatly with air conditioning systems, which act to dry the air in a building and contribute to harsh working and living environment.

Structural Performance: Rammed earth is perfectly able to act as load bearing members within a structural system. The strength of dry, un-stabilized rammed earth is close to $1 \mathrm{MPa}$. The strength and stiffness of the material reduce greatly with increasing water content, and thus the building must be well designed in order to maximize the structural potential of the rammed earth.

Feasibility: Rammed earth complies with Building Regulations for insulation, strength, water resistance, fire and acoustics. Not all soils are suitable for use as rammed earth. The soil must be compacted at a particular water content to ensure optimum compaction, and this water content should be predetermined before construction begins. Structural design of Rammed earth buildings is usually very simple, with walls acting in compression, but detailing is important to ensure the rammed earth is used to its maximum potential.

Embodied Energy: The inherent recycle-ability of rammed earth, and the reduction in $\mathrm{CO} 2$ emissions during the lifetime of the structure, the high thermal mass and thus low operating costs; all mean that rammed earth has a much lower embodied energy than comparable building materials. The following figures, adapted from Adobe and Rammed Earth Buildings, reflect the embodied energy in BTU's required for the production and use of various materials. Soil block has a much lower embodied energy than many traditional materials Easton, (1996).

Table 1

\begin{tabular}{|l|l|l|}
\hline Portland Cement & $94 \mathrm{lb}$ sack & 381,624 BTU \\
\hline Lime, hydrated & $100 \mathrm{lb}$ sack & 440,619 BTU \\
\hline Common brick & 1 block & 13,570 BTU \\
\hline Concrete block & 1 block & 29,018 BTU \\
\hline Earth (Adobe) block (mechanized production) & 1 block (10X4X14) & 2,500 BTU \\
\hline
\end{tabular}

Source: Easton, (1996)

Design Considerations: Rammed earth walls have low tensile strength, and should be reinforced by providing a bond or collar beam. Beams can be constructed of concrete, wood or steel. Vertical reinforcing may also be done, and may be required by some building officials. All openings in rammed earth walls, such as windows and doors, must have lintels to span the opening width. Water flow and moisture control is critical to protect structural walls. Special detailing to accommodate manufactured windows may be necessary to accommodate wall thickness

\section{Benefits of Rammed Earth as Ecological Stable Material}

According to (USC, 2007) It has the following ecological advantages: reduced $\mathrm{CO} 2$ emissions, thermal mass, noise reduction, high strength, durability, and low maintenance, fire resistance, pest resistance, cost effective, rapid construction, environmentally friendly, and biodegradable. Rammed Earth walls virtually maintenance free, lower homeowners insurance, energy efficient, healthy living area, and solar oriented designs, environmentally friendly and custom interior and exterior texture. Rammed Earth homes last as long as 600 years. Earth is a natural, strong, durable and healthy building material. It is also relatively inexpensive, and it retains heat, which means it can help save heating and cooling costs. It can be used in most conditions, provided it is designed and built to provide protection from rain. It has been a very common construction material all over the world. According to Earth and Sun Construction (2008), the Comparison of ecological benefit using rammed 
earth, adobe, 2x6 frames and straw- bale, as show in the Table 3 bellow illustrate the level advantages of each material.

Table 2

Comparison of Ecological Benefit Using Rammed Earth, Adobe, 2x6 Frames and Straw-bale

\begin{tabular}{|c|c|c|c|c|}
\hline & 2x6 Frame & Adobe & Straw bale & Rammed Earth \\
\hline Wall Thickness & 6 inches & 6 inches & $22-28$ inches & $18-36$ inches \\
\hline Maintenance & High & Low & Moderate & Low \\
\hline Fire Resistance & Fair & High & Fair & Very High \\
\hline $\begin{array}{l}\text { Pest/Bug } \\
\text { Resistance }\end{array}$ & Very Low & Moderate & Low & Very High \\
\hline Energy Efficiency & Fair & High & Moderate & Very High \\
\hline Thermal Mass & Very Low & Moderate & Low & Very High \\
\hline Building Style & Very Versatile & Southwest & Versatile-thick look & Versatile-thick look \\
\hline State Building Type & Standard & Standard & Alternative & Standard \\
\hline Cost & $100 \%$ & $108 \%$ & $72 \%$ & $110 \%$ \\
\hline Durability & $75-125$ yrs. & $75-200$ yrs. & Unknown & $200-600$ yrs. \\
\hline Acoustic Ability & Very Low & High & Moderate & Very High \\
\hline $\begin{array}{l}\text { Ability to Stop } \\
\text { High } \quad \text { Velocity } \\
\text { Projectile }\end{array}$ & Very Low & High & Moderate & Very High \\
\hline $\begin{array}{l}\text { Temp. Variance } \\
\text { Floor to Ceiling } \\
\text { Fahrenheit }\end{array}$ & $8-12$ & $2-3$ & $8-12$ & $2-3$ \\
\hline
\end{tabular}

Source: Earth and Sun Construction, (2008)

According to Easton (1996), he illustrates the level of satisfaction of some earth materials in term of the Commercial Status, Implementation Issues when using stone, brick and Rammed Earth for construction purpose as show in table 1 bellow.

Table 3 Level of Satisfaction of Some Earth Materials

\begin{tabular}{llllll}
\multicolumn{1}{l}{$\begin{array}{l}\text { Commercial } \\
\text { Status }\end{array}$} & \multicolumn{4}{l}{$\begin{array}{l}\text { Implementation } \\
\text { Issues }\end{array}$} \\
T & S & C & F & A & R \\
E & U & O & I & C & E \\
C & P & S & N & C & G \\
H & P & T & A & E & U \\
N & L & & N & P & L \\
O & I & C & T & A \\
L & E & & I & A & T \\
O & R & & N & N & O \\
G & S & G & C & R \\
Y & & & & E & Y
\end{tabular}

Implementation Issues

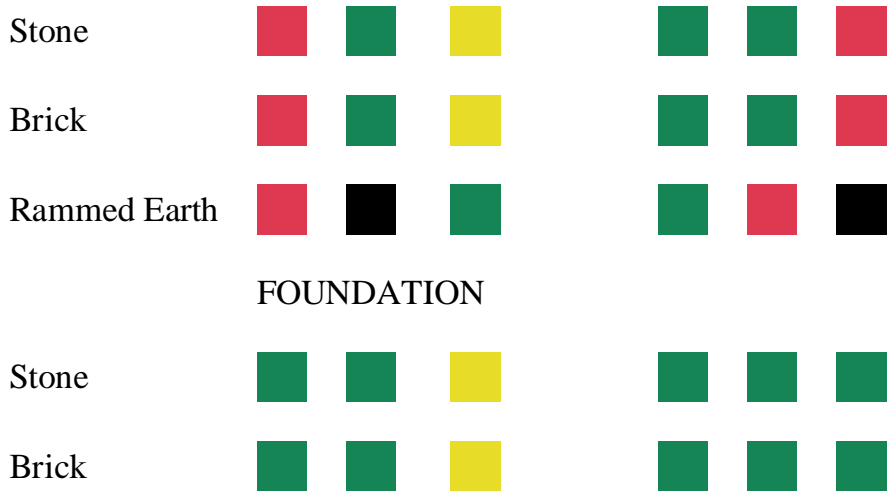


Rammed Earth
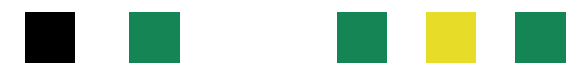

FLOOR

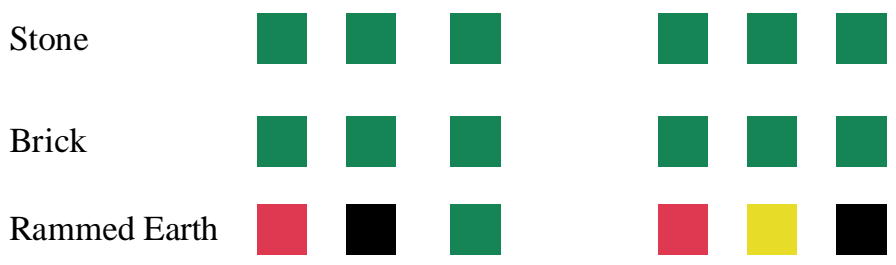

WALL

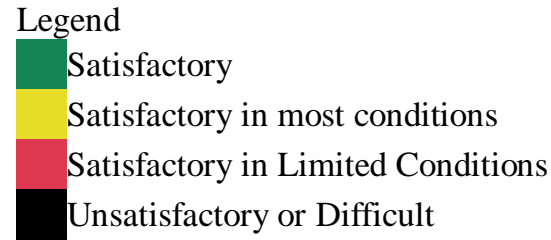

Source: Easton, 1996

\section{Environmental Aspects and Sustainability}

The use of locally available and indigenous earth materials has several advantages in terms of sustainability. They are: Reduction of energy costs related to transportation, reduction of material costs due to reduced transportation costs, especially for well-established industries, support of local businesses and resource bases. Care must be taken to ensure that non-renewable earth materials are not over-extracted. Ecological balance within the region needs to be maintained while efficiently utilizing its resources. Many local suppliers carry materials that have been shipped in from out of the area, so it is important to ask for locally produced/quarried materials (Jennifer, 2010). Both brick and stone materials are aesthetically pleasing, durable, and low maintenance. Exterior walls weather well, eliminating the need for constant refinishing and sealing. Interior use of brick and stone can also provide excellent thermal mass, or be used to provide radiant heat. Some stone and brick makes an ideal flooring or exterior paving material, cool in summer and possessing good thermal properties for passive solar heating. Caliche block has been produced for applications similar to stone and brick mentioned above. Caliche or earth material block has special structural and finishing characteristics.

Earth has proven to be one of the world's best building materials because it is historically the longest used by man, nature's product, universally available, a heavy solar mass, a natural barrier to cold winds and forces of nature (Including tornadoes, earthquakes, and hurricanes), insects and rodents, not rationed, not monopolized by anyone, a superior building material, fire proof, and sound proof. Earth has been a basic building material since the dawn of man. Architecture in earth, whether it is relatively unknown, scorned, or praised and admired, and continues to live on. It is important to point out that more than 30 per cent of the world's population continues to use earth as a building material. Whatever may happen, building in earth is presently, and will be for a long time, the only possible and logical building solution for many areas of the world. Some countries have only earth at their disposal and do not have the possibility of acquiring other material in sufficient quantity to house the large mass of their population (Civilengineergroup, 2011).

Because rammed earth structures use locally available materials, they typically have low embodied energy and generate very little waste. The soils used are typically subsoil low in clay, between $5 \%$ and $15 \%$ typically with the topsoil retained for agricultural use. Ideally, the soil removed in order to prepare the building foundation can be used, further reducing cost and energy used for transportation. Rammed earth buildings reduce the need for lumber because the formwork used is removable and can be continually reused. Rammed earth can effectively control humidity where unclad walls containing clay are exposed to an internal space. Humidity is held between $40 \%$ and $60 \%$ which is the ideal humidity range for asthma sufferers and the storage of susceptible items, such as books. When cement is used in the earth mixture, sustainable benefits such as low embodied energy and humidity control will not be realized. Manufacture of the cement itself adds to the global carbon dioxide burden at a rate of 1.25 tonnes per tonne of cement produced. Partial substitution of cement with alternatives such as ground granulated blast furnace slag has not been shown to be effective and brings other sustainability questions with it. Rammed earth can contribute to the overall energy-efficiency of buildings and the density, thickness and thermal conductivity of rammed earth makes it a particularly suitable material for passive solar heating. The material mass and clay content of rammed earth allows the building to breathe more than concrete structures, avoiding condensation issues without significant heat loss. Rammed earth housing has 
been shown to resolve problems with homelessness caused by otherwise high building costs, as well as to help address the ecological dilemma of deforestation and toxic building materials associated with conventional construction methods.

\subsection{Strategies for Sustainable Ecological Development}

With respect to the ecological dimension, sustainable development means restricting the consumption or utilisation of natural resources such that their vital functional component or their regeneration threshold is not threatened. In this sense the call for sustainability is in line with the technical requirements of environmental protection in addressing the following: the growing scarcity of natural resources, and the increasing burden and excessive strain on the absorptive capacity of environmental substrates; the knock-on impacts on environmental burdens, particularly in the domain of health; awareness of the long-term or the irreversible nature of damage to natural resources once it has occurred or is tolerated (Hugo, and Hubert, 1994).

Whenever decisions are taken, ecological concerns must be carefully harmonised with macro-economic concerns and the goal of socially compatible development. Consequently, the concretisation of this vision of sustainable development may attach different levels of significance to natural resource and landscape issues, depending on the regional or local context in question. In rural areas too, landscape spoilage is a growing problem, especially with earth construction, the utilisation of renewable natural resources must not exceed their rate of regeneration in the long term. Non-renewable natural resources should where possible, and in the long term, be utilised only on a scale at which an equivalent substitute is being created in the form of renewable resources, or in the form of higher productivity of renewable and non-renewable resources. Pollutant emissions must not exceed the self-regulating capability of the natural environment in the long term. Efficient management of water, raw materials, energy resources, prevention of noise and pollutant emissions from earth construction and joint planning frameworks and activities can help make land settlement development quantitatively and qualitatively more sustainable. In this context, the overall ecological value of a piece of land should always be taken into account. A high settlement density must not lead to a loss of all valuable undeveloped land. The natural design and greening of a settlement area is the visible objective of environmentally oriented development. Incorporation of the natural environment significantly enhances the experience and recreational value of the development, contributes to ecological networking and helps improve the local atmospheric and climatic conditions.

A policy of sustainability which seeks to combine ecological, economic and social aspects should therefore be oriented towards the following principles: spatial planning, land use planning, development planning, development land management, and bye-laws and should be employed to optimal effect. The goal of securing a decent human environment whilst at the same time protecting vital natural resources can only be successfully achieved if; soil management, open space planning, water management, building and construction, and social aspects are viewed on a comprehensive, holistic basis. The principle for setting up ecological project is to match ecological technology measures (the combination of ecological and engineering measures) to local conditions. It involves using systematic management methods, grass and tree planting technology, improvement of medium and low farmland and overall use of rural energy resources in order to tackle and improve the ecological environment.

It has been proved that grass and tree planting is a kind of multifunctional biological engineering process which produces multi benefits. Forest and grassland can provide enormous ecological benefits. The forest has constant resources and provides a green protective screen. The grassland is a community of green plants. They play an important role in protecting the natural environment. The main functions are as follows: First, they can reduce wind speed. Secondly, they can adjust the air temperature and can decrease evaporation and increase humidity. Finally, they are resistant to natural disasters. Forest and grassland can play an important role in windbreak, sand-fixation, and soil erosion reduction, and prevention of natural disasters.

\subsection{Solving Soil Ecological Problems}

Soil Conservation: Municipalities should remember that soil is not a renewable resource. Soil is the substrate of human, plant and animal production. Consequently, ecologically valuable land must be protected against changes as a matter of principle. This needs to be carefully weighed against the need to develop new land in urban areas. Necessary interventions and utilisation of land resources must be compensated through appropriate measures, such as substitution.

Building for Land Conservation: Where land is being developed for commercial and industrial use, greater emphasis should also be placed on designing building and construction measures such as to conserve land.

Ecological Procurement: Municipalities should set an example with regard to environmentally sound procurement: Procurement should not be based exclusively on the criterion of the cheapest bid, but should also take into account ecological criteria.

The situation of implementing and results: Taking into account the destroyed ecological situation and the principle of ecology, the Government should draw up a comprehensive development program in hill, water, 
forest, farmland and they should utilize the technology of ecological project to assemble and construct the environment and achieved great economic, ecological and social benefits.

VI. Design Guidelines towards Prevention of Ecological Risks.

An earth structure may be exposed to bad weather, which represents one of the major hazards leading to the deterioration of these structures. Careful examination of earth structures, in all part of the world, reveals the skills of their Architects in solving the serious problems involved in preserving the durability of structures exposed to water risks. Buildings with earth soil are particularly vulnerable to water action, it become uncomfortable or even unhealthy and runs the risk of rapid deterioration. The elimination of conditions favouring the harmful actions of water ensures that the structure remains health and lessens the risk of deterioration of the building due to the risk to chronic damp. This can be prevented by building good, deep and solid foundations and base courses, protecting the tops of walls, stabilised earth materials and reducing susceptibility to condensation. Crack and possible paths for water through the surface of walls can also be eliminated by regular maintaining the outer skin of the building. The surface of the earth walls should not be made impermeable they must be allowed to breathe and be permeable to movements of water vapour.

Good peripheral drainage is essential if water is to be kept away from the building. It must be constructed with greatest care to ensure it effectiveness. The gradient and gutters should be handling with care. The use of moisture barriers such as vertical screens on the outer surface of foundation, made with horizontal screens serving as anti-capillary course between the foundations and the base course. Such moisture barriers must be perfectly continuous and may not be cracked of defective. A damp course can be made either of water repellent cement or a bituminous product. Waterproofing should be use where daub or clay straw is used. It is wise to take steps to treats the wood particularly posts fixed in soil. Wooden posts should be embedded in the stone or concrete foundation slab. There is need to carry out termite protection on the structural timber and the masonry materials by creating chemical barrier by treating with anti-termite insecticide. Other method of prevention and strengthening earth materials are; cladding, that is made of wood or insulating materials with air space attached to the wall that increase the effectiveness of permitting ventilation and evaporation of moisture. Also the uses of long roof overhang which reduced direct effect of vertical rain washing down the earth wall and retention of soil. From observations the effect of wind and rain on walls exposed to the prevailing wind shows that it cause eddy effect on the bare surface of the wall. The effect is more pronounced if the eaves are less than $20 \mathrm{~cm}$. To limit erosion, the projection should be made wider (at lease $30 \mathrm{~cm}$ ). The use of parapets allows the roofing to be retained and gives greater control over the drainage of water and effective protection against pressure difference caused by wind. Pitched roofs with broad eaves (minimum $30 \mathrm{~cm}$ ) drain water very well and particularly well suited to earth construction. Also renovation, restoration, rehabilitation and conservation habit should be adopted and it should be on regular bases.

\subsection{Disasters-Resistant Construction towards Prevention of Ecological Risks}

The world is regularly hit by natural ecological disasters: earthquake, storms and flood. Using materials and technique which are considered as strong and safe such as reinforced concrete where majority structures are in earth. Great progress has been made in recent years in the field disaster resisting construction. Unfortunately, all too often unsuitable methods of construction are used in disaster areas. The main cause of damage is often the way in which the materials has been produced and used in construction. It has been clearly demonstrated that a well built and well maintain house can withstand the majority of earthquakes, whatever the materials or its construction. It is therefore possible to greatly reduce the risk of disaster with only a relatively small increase of the cost of construction.

Principle of Earthquake Resistant Engineering: The safety of the inhabitant of structures should come first in region with high occurrence. It is absolutely impossible to protect building perfectly and completely because of the intensity of the physical phenomena, the unpredictable nature of earthquake, and the complexity of their effects. We should therefore aim to limit the scale of the damage and to prevent the collapse of buildings. Bearing in mind the following factors: to implement codes of good practices, to guarantee a good location, to build strong structures and to guarantee proper conservation and maintenance of buildings.

Protection against Humidity: Earth structure should be perfectly protected against humidity with a proper wall base, a dam-proof course and surface rendering. A Ferro-cement rendering which is strongly connected to the structure help to resists earthquakes.

\section{Recommendations}

Avoid dividing up land on the banks of water courses, lakes or bays as these are danger of landslide and local waves. Surround the house with plantation and strong enclosures, to break the force of a wave. It is good practice not to build houses in one line, to avoid channelling and increasing the flow of the wave. Match the weight of house to the nature of the bearing soil. Deep and strong foundations, well anchored; raised wall 
bases. Make used of good masonry and durable materials for these two structural elements. Make use of reinforced and buttressed inside walls to tie the foundations to the wall and the wall to the roof. Provide openings in floors and roof to allow air and water out to reduce pressure differences and align the openings on opposite walls to avoid pressure differences.

In area exposed to exceptional tides, raised structures to above the level of the waters on dykes, embankments, landfills, wooden piles or reinforced concrete columns, etc. prevent the undermining of part of the structure by water infiltration, wind, erosion and termites, since this reduce stability. In case of heavy structure, gives preference to heavy monolithic system of rammed earth, cop or adobe. In case of light structure use a framework filled in with straw-clay or wattle and daub. Avoid earth foundation and wall bases and if there is no other choice, stabilised the earth as much as possible and avoid the use of unsterilized earth for masonry mortars. Avoid supporting roof directly on unfired earth walls, which may be eroded and those no longer able to support them. Use ring-beams and reinforcement in masonry, and avoid load bearing pillars in earth masonry, build such pillars of solid stabilised earth, with a good foundation. Rounded shape (domes vaults) and cubes are to be preferred to rectangles and choose a location with the corners facing the prevailing winds. Roof should be heavy and as streamlined as possible: domes, vaults, cones and hipped roofs. Choose a pithed of about $30^{\circ}$ to reduce the high stress to which flat roofs or those with a pitch of between 5 and $10^{\circ}$ are prone. Parapets reduce the suction effect on flats roofs. Avoid roofs overhangs of more than $50 \mathrm{~cm}$ long. Ridge ventilators reduce internal pressure.

\section{CONCLUSION}

Earth is one of the most abundant, basic building materials. It required simple method of construction technology, can easily worked with simple tools, and yet can be used by anyone to construct walls, floors and roofs of advanced architectural design. Earth buildings are highly durable, have good humidity regulation and sound insulation, and are non-toxic, non-allergenic and fireproof. They provide excellent thermal mass and insulation when built with thick walls, and when used with passive solar design. Earth buildings have very low embodied energy, and low environmental impact, especially when the material is sourced on site. As a building material, earth is the ultimate sustainable solution that is readily available. The resulting house from such materials is extremely efficient, owner friendly with limited maintenance. The resulting house is incomparable to other product in terms of beauty, efficiency, strong and stability. It is this mixture which Rammed Earth building uses, along with the pounding, compacting work done by men and pneumatic tampers that makes incredibly strong, efficient, and beautiful to look at homes. Earth Construction can offer Frame/Stucco, Adobe, and any Custom Alterations your heart desires. Earth Construction in today's world of homeless people, high costs and ecological problems in Nigeria, rammed earth can help, if it's not ignored.

The advantage of earth construction as were stated previously over the conventional material cannot be washed away. But conservational sustainability development method have to be cultivated not to endanger human existent because of treat to ecological issues which earth construction has on the ecosystem. Government should fund the environment protection agencies for proper implementation of the enabling laws. The construction industries must be concern with ecological and environmental influences of their specifications, and must design with critical information on building materials available in such a way as to minimize the strain on the earth.

\section{References}

[1] United Nations, Department for Policy Coordination and Sustainable Development National Implementation of Agenda 21; Review of Progress on Environment and Development; 1997

Civilengineergroup.Com/Wp-Content/Uploads/2011/01/Ecological and Environmental Influences

Buzzle.com, Ecology Issues; Intelligent Life on the Web 2011

G. Jennifer. (Earth and Construction: Sustainable Build.mht 2010)

Earth and Sun Construction, (2008): Site created by Digital Solutions

Schools of Architecture and the University Of Southern California@2007 USC: Rammed Earth Construction; Construction Presentation Part I, Part II.

[7] D. Easton, the Rammed Earth House: Chelsea Green Publishing United States. (1996)

[8] H Hugo, and G. Hubert, (1994): Earth Construction a Comprehensive Guide: Intermediate technology publication 